Conference Presentation

\title{
Evaluating Subtle Field Imprints in Water by Droplet Evaporation Method
}

\author{
Igor Jerman1, Petra Ratajc1, Bernhard Pollner² \\ ${ }^{1}$ Institute Bion, Ljubljana, Slovenia. Email: igor.jerman@bion.si \\ 2Pollner Research, Haspingerstrasse 7/2,6020 Innsbruck, Austria. Email: bernhard.pollner@mac.com
}

\begin{abstract}
Background: Even though water is regarded as something long understood and explained by conventional science - many open-minded researchers know that it still hides many mysteries (water clusters, coherent domains, so-called memory, etc.). Many of these mysteries come to fore in ultra-high dilution (UHD) experiments and practices, where usually not even one molecule of the originating substances is left. Mostly, they can be tackled only by using the droplet evaporation method (DEM). ${ }^{1}$
\end{abstract}

Aim: One of the hypotheses of water memory suggests that through UHD (dilutions, shaking) the field of a substance is stably impressed into water. If this is true than we should be able to imprint also a field itself - not originating from a certain substance, but from other sources. Such imprint should be revealed by an appropriate research method.

Method: The DEM consists of monitoring dried water drops by dark field microscopy. It was discovered in the previous century by Ruth Kübler, a German artist, and further developed by BerndHelmut Kröplin, Minnie Hein, Berthold Heusel M. A. and Georg Schröcker. It has also been used to research the still controversial special characteristics of ultra-high diluted aqueous solutions. ${ }^{2}$ It has been proved capable of demonstrating differences in subtle influences of an UHD (around $10^{-47} \mathrm{M}$, practically "pure" water) of $\mathrm{As}_{2} \mathrm{O}_{3}$ on common wheat seeds. This method is therefore, capable of transferring certain, not yet fully understood or generally accepted subtle physical characteristicsof the solution to the remnant patterns after drop evaporation. ${ }^{3,4}$

We used DEM to evaluate experiments on impressing the subtle field of five bioenergy healers and two so called "informed" objects (a glass and an "energy" card) into mineral or spring water with well-known characteristics. In all these experiments we also used control water that was of the same origin, but placed in a separate room. The DEM images were analyzed by special computer programs and statistically evaluated. No mother tincture of any kind was used.

Results: The results demonstrate that even such subtle fields can leave stable and reproducible imprints in water - made visually accessible by the remnant patterns after drop evaporation. The

\section{OPEN ACCESS}

Cite as: Jerman I, Ratajc P, Pollner B. Evaluating Subtle Field Imprints in Water by Droplet Evaporation Method. Proceedings of the XXIX GIRI Meeting; 2015 June 3 - 5; Verona (Italy). Int J High Dilution Res. 2015; 14(2): 15-16 
Proceedings of the XXIX GIRI Meeting; 2015 June 3 - 5; Verona (Italy). International Journal of High Dilution Research 2015; 14(2): 15-16.

Available online at www. highdilution.org

irradiated water samples were statistically different from the control. This difference can usually be observed even by a naked eye (Fig-I).

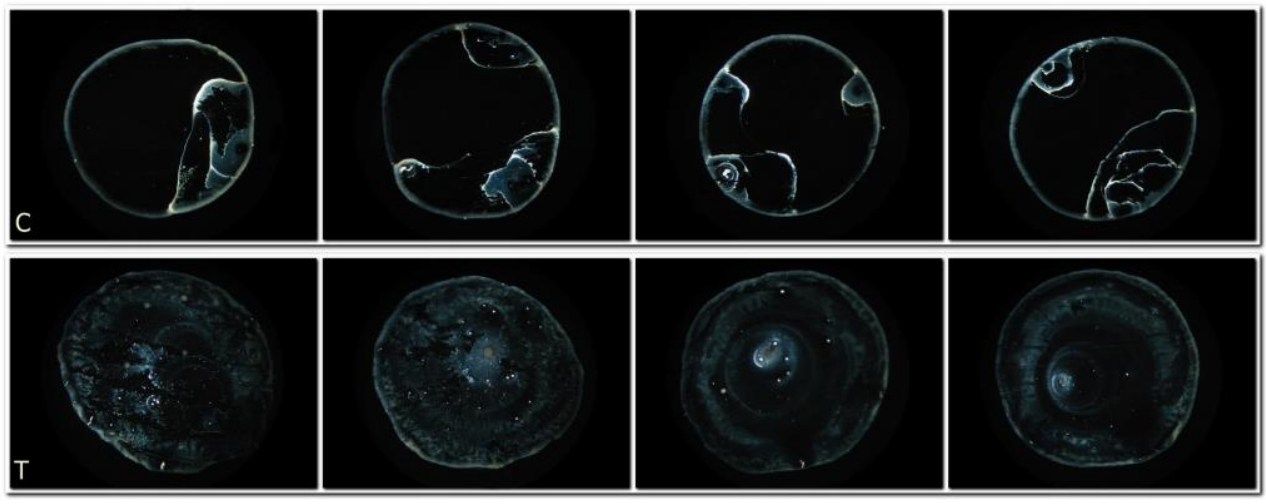

Figure - I: Typical DEM images of the chosen spring water after the irradiation from a healer. C - control water, $\mathrm{T}$ - treated water. Dark-field microscopy; $40 \times$ magnification.

\section{Conclusion}

These results have several implications. They confirm as follows:
a) water memory - the main background of UHD effects,
b) the possibility to imprint the fields into water,
c) the existence of subtle fields not yet generally recognized by physical community and
d) the capability of DEM to express the imprints.

\section{References}

1. Jerman, I. Ratajc, P. A Further Indication of the Self-Ordering Capacity of Water Via the Droplet Evaporation Method. Entropy 2014, 16(10), 5211-5222; doi:10.3390/e16105211

2. Kokornaczyk, MO, Trebbi G, Dinelli G, Marotti I, Bregola V, Nani D, Borghini F, Betti L. Droplet evaporation method as a new potential approach for highlighting the effectiveness of ultra-high dilutions. Complementary Therapies in Medicine 2014;22(2), 333-40.

3. Del Giudice E, Vitiello G. The role of the electromagnetic field in the formation of domains in the process of symmetry-breaking phase transition. Phys. Rev. A: At., Mol., Opt. Phys. 2006. 74: 022105:1-022105:16.

4. Rey L. Can low-temperature thermoluminescence cast light on the nature of ultra-high dilutions? Homeopathy 2007; 96(3):170-74.

Keywords: droplet evaporation method, field imprint, water memory

(C) International Journal of High Dilution Research.

Not for commercial purposes.

\section{OPEN ACCESS}

Cite as: Jerman I, Ratajc P, Pollner B. Evaluating Subtle Field Imprints in Water by Droplet Evaporation Method. Proceedings of the XXIX GIRI Meeting; 2015 June 3 - 5; Verona (Italy). Int J High Dilution Res. 2015; 14(2): 15-16 